\title{
Effect of Piper Nigrum (Linn) on the Toxicity Induced by Ethionamide and Para Amino Salicylic Acid Drugs on Blood Count in Sprague- Dawley Rats
}

\author{
Zodape GV and Gaikwad VS*
}

Department of Zoology, S.S. \& L.S. Patkar College of Arts and Science \& V.P. Varde College of Commerce and Economics, S.V. Road, Goregaon (West), Mumbai- 400 062, India

DOI: $10.36348 /$ sjmps.2020.v06i01.005
*Corresponding author: Dr. Zodape GV

| Received: 31.12.2019| Accepted: 07.01.2020 | Published: 15.01.2020

\section{Abstract}

Sixty six (64) Sprague- dawley rats (average weight 150 - 240 g) of each sex were used for the experiment. The animals were acclimatized, maintained and housed in laboratory for 28 days. At the end of the study animals were anesthetized and were sacrificed by cervical decapitation. Blood was collected via cardiac puncture and studied for White blood cells (WBC), Red blood cells (RBC), Haemoglobin (HGB), Hematocrite (HCT), and Platelets (PLT) by Using Operon hematology analyzer. In the present study, hematological findings among the treated and control groups of rats, we found that the hematological parameters were disturbs on the treatment of anti -TB drugs ETH and PAS. Whereas we observed that after administration of seed extract of Piper nigrum independently or in combination with the anti -TB drugs, the hematological parameters were improved towards normalization.

Keywords: anti -TB drugs; Piper nigrum; Blood.

Copyright @ 2020: This is an open-access article distributed under the terms of the Creative Commons Attribution license which permits unrestricted use, distribution, and reproduction in any medium for non-commercial use (NonCommercial, or CC-BY-NC) provided the original author and source are credited.

\section{INTRODUCTION}

Tuberculosis is an ancient scourge. Tuberculosis (TB) is one of the most ancient diseases of mankind and has co-evolved with humans for many thousands of years or perhaps for several million years [1]. In India ayurveda describes tuberculosis as Rajayakshma which means the King of diseases. Mycobacterium tuberculosis may have killed more persons than any other microbe. Skeletal deformities of tuberculosis have been found in Egyptian mummies and are clearly illustrated in early Egyptian art [2]. Nobel laureate the "founder of modern bacteriology" Robert Koch showed the world cause of tuberculosis which is the slow growing bacteria known as Mycobacterium tuberculosis [3].

Drug-induced hematological disorders can affect the red cells, white cells, platelets, coagulation, and other hematologic parameters of the body. The inhibition of hematopoiesis, immune effects, enzyme system gets affected by drug induced hematological toxicity. Drug-induced toxicity caused adverse effect on red cells and white cells by causing red cell aplasia, hemolytic anemia sideroblastic anemia, megaloblastic anemia, aplastic anemia, leucopenia, leukocytosis and many other disorders. The ETH and PAS are the second line anti- TB drugs which caused hematological disorders. The toxic, reactive metabolites of the drugs bind to cellular macromolecules and release or forms toxic free radicals intern caused the tissue damage. Medicinal plants from time immemorial have been used in virtually all cultures as a source of medicine [4]. They are considered to be the backbone of traditional medicine and are widely used to treat acute and chronic diseases. Piper nigrum is effective anti-TB. The plant is active against both drug sensitive and resistant strains of TB [5]. Hematological changes associated with tuberculosis treatments have been investigated in many parts of the world. However, to the best of our knowledge, there is no comprehensive study assessed the hematological abnormalities among TB patients in India in general and in Maharashtra in particular. Hence, this study was designed to determine the effect of anti-TB drugs on hematological profile.

\section{MATERIALS AND METHODS \\ Collection and identification of Piper nigrum (Linn) Plant}

Fresh seeds of Piper nigrum were procured from the botanical garden of Kokan Krushi Vidyapeeth, 
Dapoli, Ratnagiri. The initial identification was done by referring related literature and final identification and confirmation was done at the "Government of India, Ministry of Environment, Forest and Climate change, Botanical Survey of India, Western Regional Centre, 7, Koregaon, Road, Pune-411001.No.BSI/WRC/1001/TECH./2019/53.Prior to process the sample at the department of Zoology S.S \& L.S. Patkar College Goregaon (west), Mumbai India. After the identification of the plant ethanolic extract of the seeds was carried out by soxhlate extraction method. The sample was evaporated to dryness and powder was weighed and the yield so obtained was collected in a sterile container and kept at $-200 \mathrm{C}$ till further use. The weight of the powder was calculated based on weight of the seeds.

\section{Purchase of Ethionamide and Para aminosalicylic} acid.

The drugs ETH (Macleods Pharmaceuticals Ltd) and PAS (Lupin Ltd) were purchased following the Prescription of Physician from B.J. Medical College and Sassoon General Hospital, Pune, Maharashtra.

\section{Procurement of animals}

Sixty six (64) Sprague- dawley rats (average weight $150-240 \mathrm{~g}$ ) of each sex were used for the experiment. They were purchased and procured from the National Toxicological Centre, APT Testing \& Research Pvt. Ltd. (ATR) Pune. The experimental study was approved by Ethical committee at APT Research Foundation, Pune prior to the experimentation (CPCSEA NO. 40/PO /Re Bi Rc /S/99/. 11. 03. 2014).The animals were acclimatized, maintained and housed in APT laboratory for a week. The controlled humidity and temperature at $240 \mathrm{C}$; humidity, 12-hlight $/ 12$ hrs dark cycle was also maintained by feeding the rats with commercial rat pallets and water available ad libitum. Blood samples of the above groups were taken after 28th day by heart puncture for hematology assay.

\section{Administration of Test Article}

The test article at the above concentration was administered to each rat by a single oral gavage. The animals were dosed using a stainless steel intubation needle fitted onto a suitably graduated syringe. The dosage volume administered to individual rat was adjusted according to its most recently recorded body weight. Animal weights were determined weekly along with food consumption. Animals were randomly divided into following groups containing 8 animals (4 males and 4 females) in each group.

Table-1: Showing dosages administration of Piper nigrum, Ethionamide and Para amino salicylic acid in female rats for 28 days of study

\begin{tabular}{|l|l|l|}
\hline \multicolumn{1}{|c|}{ Groups } & \multicolumn{1}{|c|}{ Specification } & \multicolumn{1}{c|}{ Treatment specifications } \\
\hline 1 & Normal control & Rate pellets and water ad libitum \\
\hline 2 & PnS & PnS $(500 \mathrm{mg} / \mathrm{kg} \mathrm{bw})$ \\
\hline 3 & ETH & ETH $(132 \mathrm{mg} / \mathrm{kg} \mathrm{bw})$ \\
\hline 4 & PAS & PAS $(400 \mathrm{mg} / \mathrm{kg} \mathrm{bw})$ \\
\hline 5 & ETH + PAS & ETH $(132 \mathrm{mg} / \mathrm{kg} \mathrm{bw})+P A S(400 \mathrm{mg} / \mathrm{kg} \mathrm{bw})$ \\
\hline 6 & ETH + PnS & ETH $(132 \mathrm{mg} / \mathrm{kg} \mathrm{bw})+P n S(500 \mathrm{mg} / \mathrm{kg} \mathrm{bw})$ \\
\hline 7 & PAS + PnS & PAS $(400 \mathrm{mg} / \mathrm{kg} \mathrm{bw})+P n S(500 \mathrm{mg} / \mathrm{kg} \mathrm{bw})$ \\
\hline 8 & ETH + PAS + Pns & ETH $(132 \mathrm{mg} / \mathrm{kg} \mathrm{bw})+P A S(400 \mathrm{mg} / \mathrm{kg} \mathrm{bw})+P n s ~(500 \mathrm{mg} / \mathrm{kg} \mathrm{bw})$ \\
\hline
\end{tabular}

*ETH=Ethionamide, PAS=Para amino salicylic acid, PnS= Piper nigrum Linn. Seeds ethanol extract

\section{Analysis of blood sample}

At the end of the study animals were anesthetized and were sacrificed by cervical decapitation. Blood was collected via cardiac puncture and studied for White blood cells (WBC), Red blood cells (RBC), Haemoglobin (HGB), Hematocrite (HCT), and Platelets (PLT) by Using Operon hematology analyzer at APT Testing \& Research Pvt. Ltd. (ATR) Pune.

Table-2: Showing the mean concentration of haematological parameters in Sprague-Dawley rats

\begin{tabular}{|c|c|c|c|c|c|}
\hline Group & WBC $\left(\mathbf{1 0}^{\mathbf{9}} / \mathbf{L}\right)$ & $\mathbf{R B C}\left(\mathbf{1 0}^{\mathbf{1 2}} / \mathbf{L}\right)$ & HGB $(\mathbf{g} / \mathbf{d L})$ & HCT $(\boldsymbol{\%})$ & PLT $\left(\mathbf{1 0}^{\mathbf{9}} / \mathbf{L}\right)$ \\
\hline NC & 6.77 & 7.3 & 13.7 & 54.83 & 656.83 \\
\hline PnS & 6.83 & 7.2 & 13.5 & 53.88 & 782.36 \\
\hline ETH & 6.52 & 6.4 & 12.51 & 50.33 & 650.24 \\
\hline PAS & 6.74 & 6.9 & 12.46 & 49.85 & 645.82 \\
\hline ETH+PAS & 6.6 & 6.8 & 13 & 51.27 & 668.01 \\
\hline ETH+PnS & 7.1 & 7.1 & 13.07 & 54.1 & 712.13 \\
\hline PAS+PnS & 7.11 & 7.32 & 13.9 & 54.32 & 689.25 \\
\hline ETH+PAS+PnS & 7.19 & 7.13 & 13.43 & 54.62 & 715.64 \\
\hline
\end{tabular}

*Each value is the mean of 8 determinations. WBC: White blood cells; RBC: Red blood cells, HGB: Haemoglobin; HCT: Hematocrit PLT: Platelets 


\section{RESULTS AND DISCUSSION}

Table No. 1. Showing dosages administration of Piper nigrum, Ethionamide and Para amino salicylic acid in female rats for 28 days of study

Table No. 2. showng mean concentration of WBC: white blood cells, RBC: Red blood cells Hb: Haemoglobin HCT: Haematocrit and PLT: Platelets.

The highest level of WBC was observed in rats treated with ETH+PAS+PnS $\left.\left(7.19 \times 10^{9} / \mathrm{L}\right)\right)$ whereas lowest level of WBC was observed in rats treated with ETH $\left.\left(6.52 \times 10^{9} / \mathrm{L}\right)\right)$ as compared to normal untreated rats $\left.\left(6.77 \times 10^{9} / \mathrm{L}\right)\right)$. Many researchers have performed the experiments on different animal models to find the hematological effect. The study carried by $[6,7]$ have carried out the experiment on goats and they found the values of leukocytes observed leukocytosis in the experimental stages of the work may be an indication that the blood cell production increases in attempt to combat the adverse effect of increased administration of Piper nigrum extract, since leukocytes are known to be among body defense mechanisms that fight across nonself or pathogenic organism. According to [8] the lymphocytes are responsible for humoral and cellmediated immunity responses in animals. The experiments conducted by[9], on the hematological parameters of rabbit bucks in response to varied dietary treatments and this is in consonance with the reported by[10], have suggested the leukocyte counts increase during infection and stress of capture and unfavorable conditions in the animal's habitat such as shortage of food and water. White blood cells (W.B.C.'s) are the mobile defenses of the body against pathogenic infection. They also aid in the detoxification of toxic proteins and the development of immunity. Any differences in their numbers are of great significance for diagnostic and prognostic purposes [11]. The study carried by [12], reported that the Administration of Aloe vera extract brought the values of W.B.C.'s count to near normal in diabetic rats. This reduction could be due to their diminished production, redistribution from peripheral blood into the tissues or rapid destruction of W.B.C.'s [13]. The most common effects are fever, gastrointestinal disturbances, rashes and immunological reactions and other proteins [14], thus the reduction in W.B.C.'s production could arise from the drug binding to some proteins which has been reported to regulate the proliferation, differentiation and matuRatsion of committed stem cells responsible for the production of W.B.C.'S [15]. In our study it was observed decrease in total W.B.C.'s count in ETH group indicates that the drug is showing the immunomodulatory activity. The low levels of W.B.C.'S indicate the presence of leukopenia. The[16] studied the effect of Rifampicina and Isoniazid on haematological parameters and hepatotoxicity wherein they have concluded that leukopenia may be produced during the anti-TB chemotherapy treatment but there is no need to stop the treatment until and unless the W.B.C.'S count goes below $3,000 / \mathrm{mm}^{3}$ for patients with pre-treatment having W.B.C.' S count more than $4000 / \mathrm{mm}^{3}$.If the count goes below $1000 / \mathrm{mm}^{3}$ the treatment has to be stopped to avoid danger under the consultation of physician. When PnS is administered with ETH and PAS the W.B.C.'S count was maintained to normal level showing enhancement in the count of WBC although mechanism is to be studies. The study carried by [17] have reported that the metabolite of PAS have caused unrecognised type of thrombocytopenia. The study carried out by [18] found that piperine and piper longum increases the WBC count in cell line studies. With respect to above discussion it was examined that our study beholds the similar view. The study carried by [19] has reported that, the Piperine is strong alkaloid having anti platelets aggregation activity.

The highest level of RBC was observed in rats treated with PAS+PnS $\left(7.32 \times 10^{12} / \mathrm{L}\right)$ whereas lowest level of WBC was observed in rats treated with ETH $\left(6.4 \times 10^{12} / \mathrm{L}\right)$ as compared to normal untreated rats $\left(7.3 \times 10^{12} / \mathrm{L}\right)$. The low RBC count indicates anaemia, erythropoietin deficiency, however the values found are not significant but the low count was due the action of ETH. The number of RBC found highest might be the effect of $\mathrm{PnS}$ although higher number of RBC sometimes can lead to low oxygen levels, heart failure or polycythemia vera. Our study is in agreement with the study carried out by [20]. They found that, the extracts of either rosemary or parsley have no adverse effects on RBCs count or hemolysis, hemoglobin, hematocrite, blood indices (MCV, MCH \& MCHC), platelets and leucocytes values. In their study they found that oral administration with Isoniazid drug resulted in occurrence of physiological or hypochromic anemia which monitored from the significant decrease in hemoglobin content, RBCs count (erythrocytopenia), hematocrite value, $\mathrm{MCH}$, and $\mathrm{MCHC}$; also, thrombocytopenia (decrease in platelets count) and leucopenia (reduction of TLC) were recorded in compare to control group. Our results are also in accordance with the reports of [21-24] who reported that chronic application of Isoniazid induces a reduction in the number of platelets, RBCs and leukocytes through the induced oxidative stress, which might affect their life expectancy, induce an apoptosis and thereby ultimately reduce the number of these cells in the blood.

The highest level of $\mathrm{Hb}$ was observed in rats treated with PAS+PnS (13.9 g/dL) whereas lowest level of $\mathrm{Hb}$ was observed in rats treated with PAS (12.46 $\mathrm{g} / \mathrm{dL})$ as compared to normal untreated rats $(13.7 \mathrm{~g} / \mathrm{dL})$. The Low levels of $\mathrm{Hb}$ indicate the presence of anaemia. The values of $\mathrm{Hb}$ are lower in the ETH and PAS tested groups showing there is reduction in $\mathrm{Hb}$ due to the toxic metabolites produced by ETH and PAS. Our results are in agreement with the results carried out by[25, 26] 
reported that rats orally ingested toxic substances showed a decrease in hemoglobin content; they and attributed this result to one or more mechanisms; the disturbance in iron metabolism including absorption, transport and cellular uptake which led to inhibition of hemoglobin synthesis, as well as reduced erythrogenesis; and/or alternation in the activity of enzymes responsible for heme synthesis, consequently affect the production $\mathrm{RBCs}$ and $\mathrm{Hb}$ suggested that anemia is a well-known side-effect occurs as depletion in RBCs number and maturation as a consequence to INH which causes significant disturbances in hematological parameters (in humans and rats).

The highest level of HTC was observed in rats treated with ETH + PAS+PnS (54.62\%) whereas lowest level of HTC was observed in rats treated with PAS $(49.85 \%)$ as compared to normal untreated rats $(54.83 \%)$.

The highest level of PLT was observed in rats treated with PnS $\left(782.36 \times 10^{9} / \mathrm{L}\right)$ an increased number of platelets (thrombocytosis) occurs due to excessive production rate or decreased removal from the circulation in acute or chronic infections, inflammatory disease, drug induced, some myeloproliferative disorders (most cause thrombocytopenia) or malignant neoplasia. Lowest level of PLT was observed in rats treated with PAS $\left(645.82 \times 10^{9} / \mathrm{L}\right)$ as compared to normal untreated rats $\left(656.83 \times 10^{9} / \mathrm{L}\right)$. A reduced number of platelets (thrombocytopenia) occur due to decreased production and increased destruction from the body circuand is seen in bone marrow disease, uraemia, toxaemia, infection, hypoadrenocortidsm, disseminated intravascular coagulation (DIC), immunemediated disorders, myeloprolifera disorders, haemorrhage and splenomegaly. The low count of platelets is an indication of thrombocytopenia.

\section{CONCLUSION}

In the present study, hematological findings among the treated and control groups of rats, we found that the hematological parameters were disturbs on the treatment of anti -TB drugs ETH and PAS. Whereas we observed that after administration of seed extract of Piper nigrum independently or in combination with the anti -TB drugs ETH and PAS the hematological parameters were improved towards normalization. The present study was concluded that Supplementation of seed extract of Piper nigrum resulted in significant improvement in the hematological parameters might be due to its antioxidant, antistress, cytotoxic, antioxidant, hypoglycemic and anti-inflammatory properties

\section{ACKNOWLEDGEMENT}

Authors would like to thank to, Director, APT Testing \& Research Pvt. Ltd. (ATR) Pune, thanks are also due to Dr. Kishori G Apte, Dr. Bhagyshree E
Nagarkar, Dr.Gayatri Deshmukh, Dr. R.G.Khandekar for their valuable support during the experimentation.

\section{REFERENCES}

1. Hirsh, A. E., Tsolaki, A. G., DeRiemer, K., Feldman, M. W., \& Small, P. M. (2004). Stable association between strains of Mycobacterium tuberculosis and their human host populations. Proceedings of the National Academy of Sciences, 101(14), 4871-4876.

2. Cave, A. J. E., \& Demonstrator, A. (1939). The evidence for the incidence of tuberculosis in ancient Egypt. British Journal of Tuberculosis, 33(3), 142-152.

3. Koch, R. (1891). Ueber bakteriologische Forschung. Verhandlungen des X Internationalen Medichinischen Congresses, Berlin, 1890, 1, 35. August Hirschwald, Berlin.

4. Cragg, G. M., \& Newman, D. J. (2013). Natural products: a continuing source of novel drug leads. Biochimica et Biophysica Acta (BBA)General Subjects, 1830(6), 3670-3695.

5. Birdi, T., D'souza, D., Tolani, M., Daswani, P., Nair, V., Tetali, P., \& Hoffner, S. (2012). Assessment of the activity of selected Indian medicinal plants against Mycobacterium tuberculosis: a preliminary screening using the Microplate Alamar Blue Assay. European Journal of Medicinal Plants, 2(4), 308.

6. Koju, D., Rao, B.S., Shrestha, B., Shakya, R., \& Makaju, R. (2005). Occurrence of side effects from anti-tuberculosis drugs in urban Nepalese population under DOTS treatment. Kathmandu university journal of science, engineering and technology, 1(1), 1-2.

7. Oduye, O. O., \& Adadevoh, B. K. (1976). Biochemical values in apparently normal Nigerian goats. J. Nig. Vet. Med. Assoc, 5, 51-55.

8. Jain N.C. (1986). Schalm's veterinary haematology 4th edition (ed N.C. Jain) Lea and Febiger, Philadelphia, 1221.

9. Oyewale, J. O. (1991). Osmotic fragility of erythrocytes of West African Dwarf sheep and goats: Effects of temperature and $\mathrm{pH}$. British Veterinary Journal, 147(2), 163-170.

10. Ewuola, E.O., Gbore, F.A., Ogunlade, J.T., Bandyopadhyay, R., Niezen, J., \& Egbunike, G.N. (2008). Physiological response of rabbit bucks to dietary fumonisin: performance, haematology and serum biochemistry. Mycopathologia, 165(2), 99104.

11. Gotoh, S., Takennako, O., Watanabe, K., Kawamoto, R., Watanabe, T., Surgobroto, B., \& Sajuthi, O. (2001). Haematological values and parasitic fauna in free ranging Macaca hecki and the Macaca tonkeana/Macaca hecki hybrid group of Sulawesi Island, Indonesia. Primates, 42, 27-34.

12. Cavenagh, J. (2007). White blood cells. Surgery (Oxford), 25(2): 61-64. 
13. Mude, R. N., Somesula, S. R., Adi, P. J., \& Matcha, B. (2012). Diabetic regulation through blood constituents' modulations on treatment with Aloe vera in alloxan indiced diabetic rats. Dig $J$ Nanomater Biostruct, 7, 649-955.

14. DeBaun, M. R. (2005). Hydroxyurea as secondary prevention for stroke in children with sickle cell anemia. The Journal of pediatrics, 147(4), 560561.

15. Steinberg, M. H. (2005). Sickle cell disease and hydroxyurea: the good, the bad, and the future. Blood, 105(2), 441-441.

16. DeBaun, M. R. (2005). Hydroxyurea as secondary prevention for stroke in children with sickle cell anemia. The Journal of pediatrics, 147(4), 560561.

17. Eisner, E. V., \& Kasper, K. (1972). Immune thrombocytopenia due to a metabolite of paraaminosalicylic acid. The American journal of medicine, 53(6), 790-796.

18. Sunila, E. S., \& Kuttan, G. (2004). Immunomodulatory and antitumor activity of Piper longum Linn. and piperine. Journal of ethnopharmacology, 90(2-3), 339-346.

19. Son, D., Akiba, S., Hong, J., Yun, Y., Hwang, S., Park, Y., \& Lee, S. (2014). Piperine inhibits the activities of platelet cytosolic phospholipase A2 and thromboxane A2 synthase without affecting cyclooxygenase-1 activity: Different mechanisms of action are involved in the inhibition of platelet aggregation and macrophage inflammatory response. Nutrients, 6(8), 3336-3352.

20. Khaled, G., Abdel-Wahhab.1., Abdel-Baset, M.A., Abd E-Reheem., Mohammed, M., Abdel-Wahhab., Salah M. E. Soliman., Mahmoud, A. (2018). Rosemary and parsley extracts minimize Isoniazid -induced hematological deterioration and enhance the oxygenation potential in adult male albino rats; JIPBS, 5(2), 93-100.

21. Awe, E.O., \& Banjoko, S.O. (2013). Biochemical and haematological assessment of toxic effects of the leaf ethanol extract of Petroselinum crispum (Mill) Nyman ex A.W. Hill (Parsley) in rats. BMC Complementary and Alternative Medicine, 5: 1375.

22. Al-Awaida, W., \& Akash, M. (2014). Protective role of aqueous medicinal herbal extracts against oxidative stress on glucose-6-phosphate dehydrogenase activity and RBC fragility. Life Sci $J, 11(2), 385-91$.

23. Badar, T., Cortes, J. E., Ravandi, F., O'Brien, S., Verstovsek, S., Garcia-Manero, G., \& Borthakur, G. (2015). Phase I study of S-trans, transfarnesylthiosalicylic acid (salirasib), a novel oral RAS inhibitor in patients with refractory hematologic malignancies. Clinical Lymphoma Myeloma and Leukemia, 15(7), 433-438.

24. Abdel-Ghaffar, O., Mahmoud, S. T., Said, A.A., \& Sanad, F. A.A.Y. (2018). Ameliorative effect of rutin against isoniazid-induced alterations in certain hematological and biochemical parameters of albino rats. International Journal of Pharmacology, 14, 39-51.

25. El-Reheem, A., \& Zaahkcuk, S. (2007). Protective effect of Vitamin $\mathrm{C}$ and selenium against the toxicity induced by lead acetate on some physiological parameters in blood of male albino rats. Bulletin of Egyptian Society for Physiological Sciences, 27(1), 59-76.

26. Ergul, Y., Erkan, T., Uzun, H., Genc, H., Altug, T., \& Erginoz, E. (2010). Effect of vitamin C on oxidative liver injury due to isoniazid in rats. Pediatrics International, 52(1), 69-74. 